\section{The Competitive Structure and Strategic Positioning of the Bank Industry in the Face of Major Environmental Disturbances: A Study of Brazilian Banks}

\author{
Gisele Walczak Galilea ${ }^{\dagger}$ \\ FGV/EAESP \\ William Eid Junior ${ }^{\Omega}$ \\ FGV/EAESP
}

\begin{abstract}
This work looks into the dynamics of the competitive structure and strategic positioning of Brazilian banks. Over the eighteen years covered by the study, we saw periods of strategic instability in this industry and differing structures of strategic groups, with regard to not only their number, but also their composition. Our study therefore provides empirical evidence that we will hardly find periods of full strategic stability. These findings denote that, at some moment, there is a change in the strategic positioning of these firms and provides insight with regard to the competitive patterns of an industry over the period.
\end{abstract}

Keywords: Brazilian bank strategy; Strategic groups; Industrial organization theory; MCLUST.

\section{INTRODUCTION}

The conduct and performance of firms and industries are topics that have aroused considerable scientific interest for some time. A logical understanding with regard to the operating methods of the firms and industries was originally the prime objective of literature on Industrial Organization (IO).

The theory then based on the paradigm of "structure-conductperformance" posited that for a particular sector there would be an ideal strategy to be followed and therefore, variances in the profitability of the companies would be the result of a scale economy (Mason, 1949 and Bain, 1959). However, Hunt's observations in 1972 showed the presence of groups in the same sector with different strategies and thus a new line of investigation was born.

The treatment of the strategic groups provided a new characterization of the facts. This work is focused on this treatment. Questions such as the dynamics of the competitive structure and strategic positioning of the firms and industries are of great academic interest. However, the analysis on the conduct of strategic groups over time seems to be a suitable vehicle for a look into the history and evolution of a market.

Empirical studies by Cool (1985), Cool \& Schendel (1987), Fiegenbaum (1987), Mascarenhas (1989) and Fiegenbaum \& Thomas's (1990), looked into the basic questions with regard to the composition of strategic groups, their evolution and the kinds of change to which they had been subjected from a dynamic perspective. These works gave rise to a series of similar studies during the 1990s.
Corresponding author:

${ }^{\dagger} \mathrm{FGV} / \mathrm{EAESP}$

E-mail: gwsilva@yahoo.com.br

$\Omega$ FGV/EAESP

E-mail: william.eid@fgrvbr

Received: 07/28/2015.

Revised: 11/10/2015

Accepted: 03/21/2016.

Published Online: 02/01/2017. 
However, some restrictions should be highlighted, as pointed out by Zúñiga et al (2004), with regard to these studies, that on the one hand, in their analysis, the majority covered a period characterized by stability in the environmental conditions, and on the other hand made use of stable samples of companies, these being comprised of the largest companies in the industry.

In line with the Zúñiga et al (2004) study, we examined, by means of statistical analysis, the dynamics of the competitive structure and strategic rank of a specific industry, the Brazilian banking market. Over the period analyzed, the firms in this industry were subject to continual environmental disruptions and furthermore, this is an industry characterized by changes in its composition (bankruptcies, mergers, takeovers and privatizations).

Although our study is clearly in line with the research of Zúñiga et al (2004), the differences relate to the variables that characterize current strategic activities. One of the gaps in the Zúñiga et al (2004) study is in the research into the strategic rank of Spanish banks by means of the variables that only characterize this strategic rank at business level (types of consumers and products), whereas our study fills in these gaps by expanding the research to the operational level (decisions with regard to the commitment of resources) by using data on the capital equity structure and the results of the banks. According to Amel \& Rhoades (1988) the commitment of resources (raising of capital policies and investment of funds) and the business environment (type of consumer, products and risks) is reflected in these structural decisions.

This work is organized in five sections. The next section shows a review of the literature on research that contributes to the understanding of the field of the study and other aspects connected to our study. In section 3, we detail the study variables and methodology used in the analysis of the data. In section 4, we show and discuss the results and evidence obtained. Finally, in section 5 we conclude our work.

\section{THE LITERATURE OF THE STRATEGIC GROUPS}

The treatment of the strategic groups arises from an attempt to fill in the existing gaps in the industrial organization theory with regard to the paradigm "structure-conductperformance". The term "strategic group" was originally coined by Hunt (1972), who identified the strategic differences between firms in American industry, which divided white goods into four groups on the basis of three strategy sizes (asymmetries existing in that industry).

These groups were called strategic groups and defined by the author as being firms in the same industry that are highly symmetrical with regard to their cost structure, degree of vertical integration, degree of product differentiation, formal organization, control systems, management remuneration and sanctions, and lastly their personal views and preferences with regard to the various possible results.

The concept of strategic groups was developed from two points of view, the first emanating from the industrial organization school (Hunt, 1972; Newman, 1973; Porter, 1973; Caves \& Porter, 1977; Newman, 1978 and Oster, 1982), and the second from the school of strategic management (Hatten, 1974; Patton, 1976 and Cool, 1985).

From the perspectives of the industrial organization school, measures such as the size of the firm (Porter, 1973 and 1979), the number of agents in an industry (Porter 1976, Oster 1982) and the degree of vertical integration (Newman, 1973) were taken as proxies for the strategy and therefore related to the performance to thus explain the existing differences.

For its part, the strategic management school treated the strategic groups from a different perspective. Starting from the idea that these groups comprise a useful analytical tool to bring together firms with similar strategies to provide comparisons, this line of research is concentrated on the individual firms and their competitive patterns using many variables 
BBR

14,4

linked to the strategy so as to identify the strategic groups in one particular industry (Hatten, 1974; Patton, 1976 and Cool, 1985).

By the mid 80's, a new phase of research now focused on matters such as the exploration of mobility barriers (McGee \& Thomas, 1986 and Mascarenhas \& Aaker, 1989) and the stability of the strategic groups (Oster, 1982; Cool, 1985; Cool \& Schendel, 1987; Cool \& Schendel, 1988; Fiegenbaum, 1987; Mascarenhas, 1989 and Fiegenbaum \& Thomas, 1990).

Although the dynamics of the strategic groups had been repeatedly documented in longitudinal studies of the conduct of groups, significant methodological differences were observed in said empirical studies.

There are works in which the method of defining the time period during which the group structures do not undergo significant changes is subjective, these periods being determined a priori by means of knowledge of the sector being analyzed (Amel \& Rhoades, 1988 and 1992; Ketchen, Thomas \& Snow, 1993) in addition to studies in which technical statistics (among which are of Hotelling's $\mathrm{T}^{2}$ test and the Box's M test) are used to objectively define the periods of strategic stability (Cool \& Schendel, 1987 and 1988; Fiegenbaum \& Thomas, 1990 and 1993; Fiegenbaum et al, 1990; Flavián \&

It is worth highlighting that the Amel \& Rhoades' (1988) study, although it defines the periods of strategic stability subjectively, deserves attention because it brings in as an innovation, the use of financial statement data as variables that characterize the strategic activity of the firm.

In line with the works that objectively define the time period in which the group structures do not undergo any significant changes, researches can be seen that also turn their attention to the circumstances that affect the classification of the firms (Mascarenhas, 1989; Bogner, 1991 and Zúñiga et al. 2004).

The study Mascarenhas (1989), a dynamic analysis of the strategic groups in the petroleum industry, had already provided data with regard to a connection between the mobility of strategic groups and environmental changes. For his part, Bogner (1991) studied the dynamics of strategic groups in the American pharmaceutical industry and tested various hypotheses as to why firms changed their strategic rank and under what circumstances this occurred. Within the set of questions explored by the author, some pondered the possibility of changes in the firms in the strategic groups during periods of instability.

Contrary to what was expected, the empirical results obtained by Bogner (1991) showed changes at various times and not only during times of upheaval. The work of Zúñiga et al (2004) backed up these results. One of the assumptions in this study is that at some point in time almost all industries show firms that move from one strategic group to another when the total number of companies in the industry is considered.

The authors recognize that the existence of periods of strategic stability shown in previous studies is linked to the sample now selected by researchers (the largest companies in an industry) and empirically show that, taking into account a population of companies that have over time been subject to environmental disturbances and largely made up of small units, there is no strategic stability since, at some time or another, these companies move from one strategic group to another, contradicting other studies among which is that of Cool \& Schendel (1987).

As regards Brazil, specifically considering studies related to the banking industry, only the existence of strategic groups was explored by Savoia \& Weiss (1995) and Gonzalez; Savoia \& Gouvêa (2008) and up to now there are no works that deal with the stability of strategic groups in the banking industry and the influences exerted by new environmental conditions on groups' strategic patterns. 


\section{DATA AND METHODOLOGY}

The identification and specification of the variables that best reflect the strategic rank of a firm depend on the selected industry (Cool \& Schendel, 1987). For the selected population in this study, the strategic activity was linked to decisions within the firm environment (type of consumers, products and risks) and decisions with regard to the commitment of resources (resources and investment of funds policies), since the selection of the variables that characterize this strategic activity are based on a review of the literature on the strategic groups in the Brazilian banking industry.

With the purpose of examining the relation between the upheaval in the environmental conditions and the changes that took place over the period in the competitive structure of the Brazilian banks, we used variables similar to those of the Gonzalez; Savoia \& Gouvêa (2008) study, which are described in Table 1. These variables were selected from the balance of these financial organizations. The balance composition of these financial firms may be a very good indication of the different financial products and services that each banking firm competes with in their different market segments and their use made it possible to eliminate potential arbitrariness in the choice of the variables that characterize strategic activity (Amel \& Rhoades, 1988).

Table 1. Work study variables
BBR

14,4

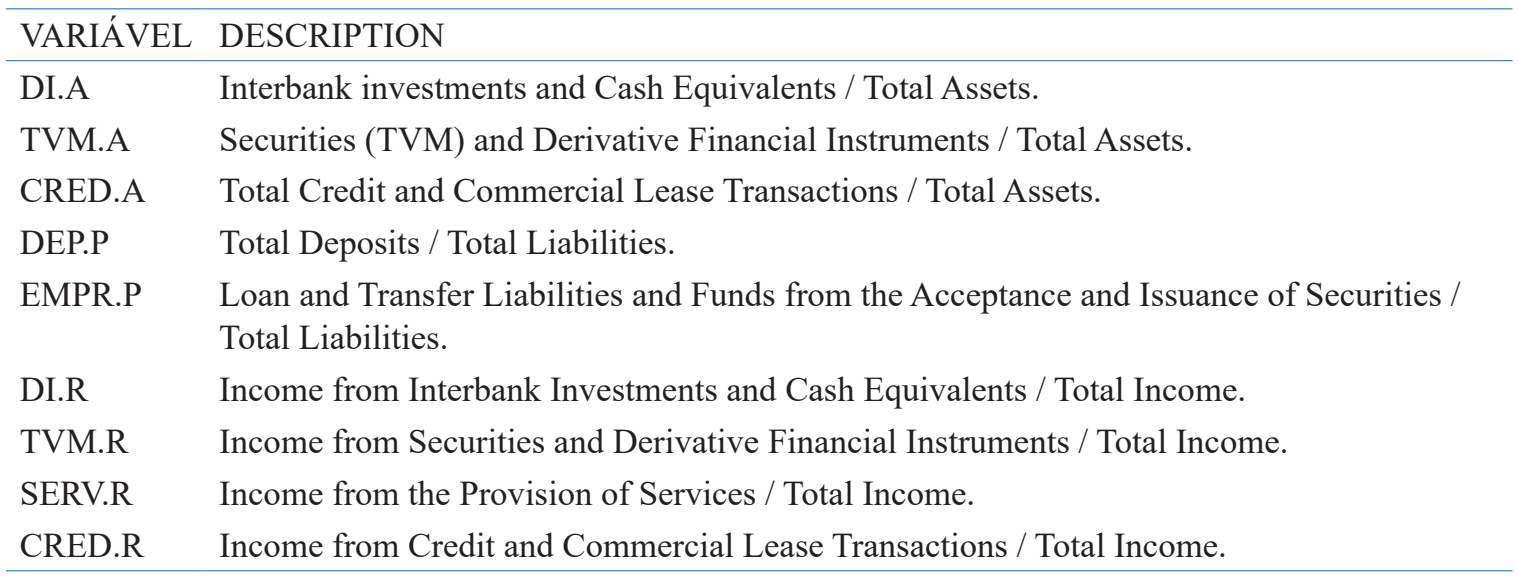

This study uses 18 years of data from 533 different banks the period from 1994 to 2011 . These banks represented the complete population of Brazilian banking institutions during this period (non-banking institutions and credit cooperatives are not considered). The basic information used for the strategic variables was taken from the yearly reports published by the Brazilian Central Bank. These reports provided detailed balance data, we use all the annual reports from December 1994 to December 2011.

From the study variables thus shown, we made a specific description of the methods for defining the strategic stability periods and strategic groups. Our study, like other works (Fiegenbaum \& Thomas, 1990 and 1993; Fiegenbaum et al, 1990; Flavián \& Polo, 1998; Más, 1999; Zúñiga et al, 2004), followed a similar methodology as that of Fiegenbaum et al (1987). The periods of strategic stability are defined as those which meet the dual condition that the variance-covariance matrix, as well as the average vector of the strategic variables remains relatively stable.

In this context, strategic instability comes into play the moment there is an infringement of one of the two criteria posited by Fiegenbaum et al (1987). Thus, two statistical tests are applied to the two strategic stability criteria. For the first, the Box's M test is used for the purpose of testing the equality of the covariance matrixes of the strategic variables and 
BBR

14,4

372

the Hotelling's $\mathrm{T}^{2}$ test is therefore used to test the second criteria, i.e., the equality of the average strategic variable vectors.

Box's $M$ test is defined as follows:

$\mathrm{H} 0: \sum 1=\sum 2$

$\mathrm{H} 1: \sum 1 \neq \sum 2$,

where $\sum$ represents the variance-covariance matrix associated with strategic variables in a certain period.

In case the null hypothesis is not rejected, these two periods are regarded jointly and create a new covariance matrix $\sum 12$. Then a third period is included and the null and alternative hypotheses are reformulated as follows:

$\mathrm{H} 0: \sum 12=\sum 3$

$\mathrm{H} 0: \sum 1=\sum 23$

H1: all $\sum$ are not equal,

where $\sum 12$ and $\sum 23$ are the variance-covariance matrices of strategic variables jointly considered in the two first periods and the two last periods.

In case both null hypotheses are accepted, the three periods are regarded as one period of strategic stability and they are grouped together. The next steps in the evaluation of periods of strategic stability will follow the same logic.

Hotelling's $\mathrm{T}^{2}$ test is important for the situation in which the mean values of strategic variables may change, as it indicates a new strategic positioning without altering the values in the variance-covariance matrix of strategic variables. The logic of this test is similar to the one described in Box's M test.

The strategic instability means that Brazilian banks have changed their strategic position annually in terms of the decisions within the firm environment (type of consumers, products and risks) and decisions with regard to the commitment of resources (resources and investment of funds policies), i.e. in terms of the nine strategic decision variables of Table 1.

For the building of the strategic groups, or clusters, one of the most frequently used methods is the hierarchical model-based clustering method developed by Banfield \& Raftery (1993). This method enables the investigation of the heterogeneity of a population by means of a finite mixture model in which each grouping is described by a different probability density function so that:

$$
f(x)=\sum_{k=1}^{g} \pi_{k} f_{k}(x) \text {, being that } 0 \leq \pi_{k} \leq 1 \text { and } \sum_{k=1}^{g} \pi_{k}=1 \quad \text { (1), where: }
$$

$\mathrm{x}$ is a finite mixture of $\mathrm{g}$ components (each mixture component is a distinct cluster) with a probability density function defined in accordance with the formula (1);

$\pi_{\mathrm{k}}$ are the proportions or weights of the mixture, i.e., consist of the is the probability that an observation comes from the $\mathrm{k}^{\text {th }}$ mixture component;

$\mathrm{f}_{1}(),. \ldots, \mathrm{f}_{\mathrm{g}}($.$) are called mixture density components and represent any distribution.$

However, considering $\left.\mathrm{f}_{\mathrm{k}}(\mathrm{x})=\mathrm{f}_{\mathrm{k}}(\mathrm{x}) \mid \theta_{\mathrm{k}}\right)$ for $\mathrm{k}=1,2, \ldots$, g, i.e., the density components of the mixture belonging to a parametric family, $\theta_{\mathrm{k}}$ being a vector of unknown parameters of the $\mathrm{k}^{\text {th }}$ density component of the mixture, the formula (1) can be re-written as follows:

$$
f(x \mid \theta, \pi)=\sum_{k=1}^{g} \pi_{k} f_{k}\left(x \mid \theta_{k}\right) \quad \text { (2), where: }
$$

$\pi_{\mathrm{k}}$ consists of the probability associated with each component of the mixture to produce the observations $x=\left(x_{1}, \ldots, x_{n}\right)$. 
The vector containing all unknown parameters, $\theta_{\mathrm{k}}$ is estimated by applying the maximum likelihood method using the EM (Expectation-Maximization) algorithm. The likelihood function is built starting from formula (2), thus:

$$
L_{\text {mix }}\left(\theta_{1}, \ldots, \theta_{g} ; \pi_{1}, \ldots, \pi_{g} \mid x\right)=\prod_{i=1}^{n}\left\{\sum_{k=1}^{g} \pi_{k} f_{k}\left(x_{i} \mid \theta_{k}\right)\right\} \quad \text { (3), where: }
$$

the vector $x_{i}=x_{i 1}, x_{i 2}, \ldots, x_{\text {in }}$ for $i=1,2, \ldots, n$.

In this study, for building the strategic groups or clusters, we followed Zúñiga et al (2004), who used the Model-based Clustering (Mclust) computer model. By means of this model, it is possible to make an analysis of the clusters using the hierarchical model-based clustering method posited by Banfield \& Raftery (1993).

The Mclust therefore, makes it possible to obtain the best possible solution that does not refer to the number of clusters, thus the choice of this number does not depend on the subjective judgment of the researcher as seen in cases where traditional hierarchic and nonhierarchic models are used. In Mclust, each cluster is described by a probability density function $\Phi_{\mathrm{k}}$ of a normal multivariate distribution parameterized by the average vectors $\mu_{\mathrm{k}}$ and the covariance matrix $\Sigma_{\mathrm{k}}$ :

$$
\phi\left(x_{i} \mid \mu_{k}, \Sigma_{k}\right)=\frac{\exp \left\{-\frac{1}{2}\left(x_{i}-\mu_{k}\right)^{T} \sum_{k}^{-1}\left(x_{i}-\mu_{k}\right)\right\}}{\sqrt{\operatorname{det}\left(2 \pi \Sigma_{k}\right)}} \quad \text { (4), where: }
$$

the vector $x_{i}=x_{i 1}, x_{i 2}, \ldots, x_{\text {in }}$ for $i=1,2, \ldots, n$.

$\mathrm{k}$ is the full number that identifies a particular cluster,

$\left(\mathrm{x}_{\mathrm{i}}-\mu_{\mathrm{k}}\right)^{\mathrm{T}}$ is a transposed matrix,

$\Sigma_{\mathrm{k}}^{-1}$ is an inverse matrix.

The parameters $\pi_{\mathrm{k}}, \mu_{\mathrm{k}}$ and $\Sigma_{\mathrm{k}}$ are estimated by means of the likelihood function shown in formula (5) by applying the maximum likelihood method using the EM (ExpectationMaximization) algorithm.

$$
\prod_{i=1}^{n}\left\{\sum_{k=1}^{g} \pi_{k} \phi\left(x_{i} \mid \mu_{k}, \Sigma_{k}\right)\right\}
$$

It should be emphasized that the characteristics of a cluster expressed by means of the $\Sigma_{\mathrm{k}}$ covariance matrix can vary and therefore it is possible to build several models for different parameterizations of this matrix. Another aspect has to do with the number of components that make up the population. Insofar as this number is unknown it is necessary to use a selection technique of the models to estimate the number of components. Thus, in order to choose the best model and determine the number of components (groups) of the mixture, the Bayesian Information Criterion (BIC) is used. This criterion, shown in formula (6), consists of a close estimate of the integral likelihood. In the end, the greater the value of the $\mathrm{BIC}$ statistic, the stronger is the evidence in favor of the corresponding model.

$$
B I C(M)=2 \Lambda(M)-k(M) \log n \quad \mathbf{( 6 )}, \text { where: }
$$

$\Lambda$ is the maximum log-likelihood on model $\mathrm{M}$,

$\mathrm{k}$ is its complexity, i.e., the number of parameters,

$\mathrm{n}$ is the size of the sample.

Changes in the strategies of the group are studied as in Más (1999) by means of a comparison of the strategic groups and their key strategic variables in consecutive periods. 
BBR

14,4

As the changes are already arranged in the groups (the number of members of the groups), they are studied in each period by means of a mobility rate, this being the calculation of the probability that a firm moves around in strategic groups in consecutive periods in accordance with the procedure developed by Sudharshan et al (1991). Finally, the changes in the number of strategic groups in the Brazilian banking industry are gathered, observing increases and decreases in groups for each period.

\section{RESULTS}

Empirical studies on the dynamics of strategic groups state that, when there is a sudden change in environmental conditions, it is possible to observe a period of strategic instability in an industry. However, there are some differences among these studies regarding the effect of such environmental disturbance on the competitive structure and strategic positioning of firms. In order to empirically show that, taking into account a population which is subject to continuous changes in environmental conditions, there are significant alterations in the competitive strategy of strategic groups (changes in groups' competitive standards) and instability in such groups (variation in the number of groups), it is necessary to identify which are the periods of strategic stability (i.e. periods of homogeneity and similarity in the competitive behavior of firms) and the strategic groups in each period.

In order to define the time period when the structure of the strategic groups was not subject to significant changes, we carried out the Box's M test and the Hotelling's $\mathrm{T}^{2}$ test. However, Cool \& Schendel (1987) state that the determination of the strategic transition points may be affected by the composition of the sample being used, a supplementary analysis being required to verify the sensitivity of the results to the composition of the sample.

The approach suggested by the authors consists in determining the strategic transition points on a "q" sample of companies where " $\mathrm{q}<\mathrm{n}$ " and repeat this analysis several times, adding companies until the total " $n$ " of the sample is obtained. We followed this approach and repeated the aforementioned tests for randomly selected bank samples, the results obtained being shown in Table 2 .

The existence of strategic instability can be inferred from the violation, for any of the randomly selected samples of banks, of one of the following conditions: (i) the variancecovariance matrix remains relatively stable; (ii) the vector of the mean of strategic variables remains relatively stable.

We observe that in almost all studied years, for at least one of the randomly selected samples of banks, the null hypothesis about the equality between the covariance matrices (Box's $M$ test) or the vectors of the mean of strategic variables (Hotelling's $\mathrm{T}^{2}$ test) is rejected. Except for the years 1994 and 1995, there is high strategic instability. A possible explanation for such high level of strategic instability are the continuous environmental changes to which the firms of this industry have been subject.

A series of events - the main ones are chronologically presented in Table 3 - had an effect on the Brazilian banking industry throughout history. Such environmental disturbances may be considered as explanations for disruptions to strategic stability, i.e. they have resulted in the need for Brazilian banks to reformulate their strategies in order to adapt to the new conditions imposed by the environment.

The results shown here are in line with the work of Zúñiga et al (2004). Taking into account that each year is associated to a transition point of competitive standards of banks, we will test our explanation for the high level of strategic instability through the identification of strategic groups in each analyzed year.

The Brazilian banking sector experienced remarkable episodes which triggered significant changes in their composition. Many banks did not easily adapt to the new environmental 
Table 2. Tests of the equality of the variance-covariance matrix and the average vector of the variables

\begin{tabular}{|c|c|c|c|c|c|c|c|}
\hline $\begin{array}{l}\text { Year Pairs } \\
\text { Compared }\end{array}$ & $\begin{array}{c}\text { Sample Size } \\
n=\end{array}$ & M Box & $\mathrm{F}$ & Probability & $\mathrm{T}^{2}$ & $\mathrm{~F}$ & Probability \\
\hline \multirow{4}{*}{ 1994-1995 } & 533 & 182.632 & 3.986 & 0.000 & 0.266 & 15.468 & 0.000 \\
\hline & 453 & 176.499 & 3.841 & 0.000 & 0.272 & 13.495 & 0.000 \\
\hline & 400 & 261.674 & 5.681 & 0.000 & 0.281 & 12.597 & 0.000 \\
\hline & 346 & 238.054 & 5.155 & 0.000 & 0.318 & 12.824 & 0.000 \\
\hline \multirow{4}{*}{ 1995-1996 } & 524 & 196.742 & 4.293 & 0.000 & 0.044 & 2.524 & 0.008 \\
\hline & 445 & 179.471 & 3.902 & 0.000 & 0.039 & 1.851 & 0.058 \\
\hline & 393 & 136.113 & 2.948 & 0.000 & 0.051 & 2.078 & 0.031 \\
\hline & 341 & 161.971 & 3.494 & 0.000 & 0.058 & 2.031 & 0.036 \\
\hline \multirow{4}{*}{ 1996-1997 } & 504 & 107.398 & 2.342 & 0.000 & 0.061 & 3.370 & 0.001 \\
\hline & 428 & 72.940 & 1.584 & 0.008 & 0.073 & 3.340 & 0.001 \\
\hline & 378 & 126.913 & 2.751 & 0.000 & 0.079 & 3.280 & 0.001 \\
\hline & 328 & 87.832 & 1.895 & 0.000 & 0.076 & 2.700 & 0.005 \\
\hline \multirow{4}{*}{ 1997-1998 } & 478 & 50.736 & 1.105 & 0.291 & 0.024 & 1.223 & 0.278 \\
\hline & 406 & 90.045 & 1.955 & 0.000 & 0.029 & 1.288 & 0.241 \\
\hline & 359 & 110.265 & 2.383 & 0.000 & 0.030 & 1.141 & 0.333 \\
\hline & 311 & 73.058 & 1.573 & 0.008 & 0.031 & 1.034 & 0.413 \\
\hline \multirow{4}{*}{ 1998-1999 } & 453 & 67.310 & 1.464 & 0.023 & 0.065 & 3.213 & 0.001 \\
\hline & 385 & 70.514 & 1.527 & 0.013 & 0.055 & 2.242 & 0.019 \\
\hline & 340 & 41.630 & 0.899 & 0.665 & 0.090 & 3.223 & 0.001 \\
\hline & 294 & 48.950 & 1.054 & 0.374 & 0.062 & 2.055 & 0.033 \\
\hline \multirow{4}{*}{ 1999-2000 } & 434 & 177.672 & 3.862 & 0.000 & 0.015 & 0.713 & 0.697 \\
\hline & 369 & 175.321 & 3.796 & 0.000 & 0.019 & 0.743 & 0.670 \\
\hline & 326 & 142.223 & 3.068 & 0.000 & 0.013 & 0.436 & 0.915 \\
\hline & 282 & 224.330 & 4.822 & 0.000 & 0.030 & 0.943 & 0.488 \\
\hline \multirow{4}{*}{$2000-2001$} & 417 & 188.419 & 4.092 & 0.000 & 0.017 & 0.791 & 0.625 \\
\hline & 354 & 304.868 & 6.596 & 0.000 & 0.030 & 1.184 & 0.304 \\
\hline & 313 & 172.118 & 3.709 & 0.000 & 0.037 & 1.241 & 0.269 \\
\hline & 271 & 42.102 & 0.900 & 0.662 & 0.060 & 1.636 & 0.106 \\
\hline \multirow{4}{*}{$2001-2002$} & 397 & 42.931 & 0.931 & 0.604 & 0.040 & 1.714 & 0.084 \\
\hline & 337 & 102.148 & 2.208 & 0.000 & 0.057 & 2.125 & 0.027 \\
\hline & 298 & 66.298 & 1.425 & 0.032 & 0.450 & 1.407 & 0.184 \\
\hline & 258 & 78.184 & 1.674 & 0.003 & 0.033 & 0.938 & 0.493 \\
\hline \multirow{4}{*}{$2002-2003$} & 384 & 43.191 & 0.936 & 0.595 & 0.028 & 1.145 & 0.330 \\
\hline & 326 & 72.446 & 1.563 & 0.009 & 0.031 & 1.082 & 0.376 \\
\hline & 288 & 59.280 & 1.273 & 0.103 & 0.046 & 1.397 & 0.189 \\
\hline & 250 & 77.817 & 1.663 & 0.003 & 0.045 & 1.200 & 0.296 \\
\hline \multirow{4}{*}{ 2003-2004 } & 378 & 93.879 & 2.034 & 0.000 & 0.029 & 1.176 & 0.309 \\
\hline & 321 & 102.510 & 2.211 & 0.000 & 0.036 & 1.236 & 0.272 \\
\hline & 284 & 191.399 & 4.113 & 0.000 & 0.055 & 1.705 & 0.088 \\
\hline & 246 & 103.269 & 2.202 & 0.000 & 0.072 & 1.814 & 0.067 \\
\hline
\end{tabular}




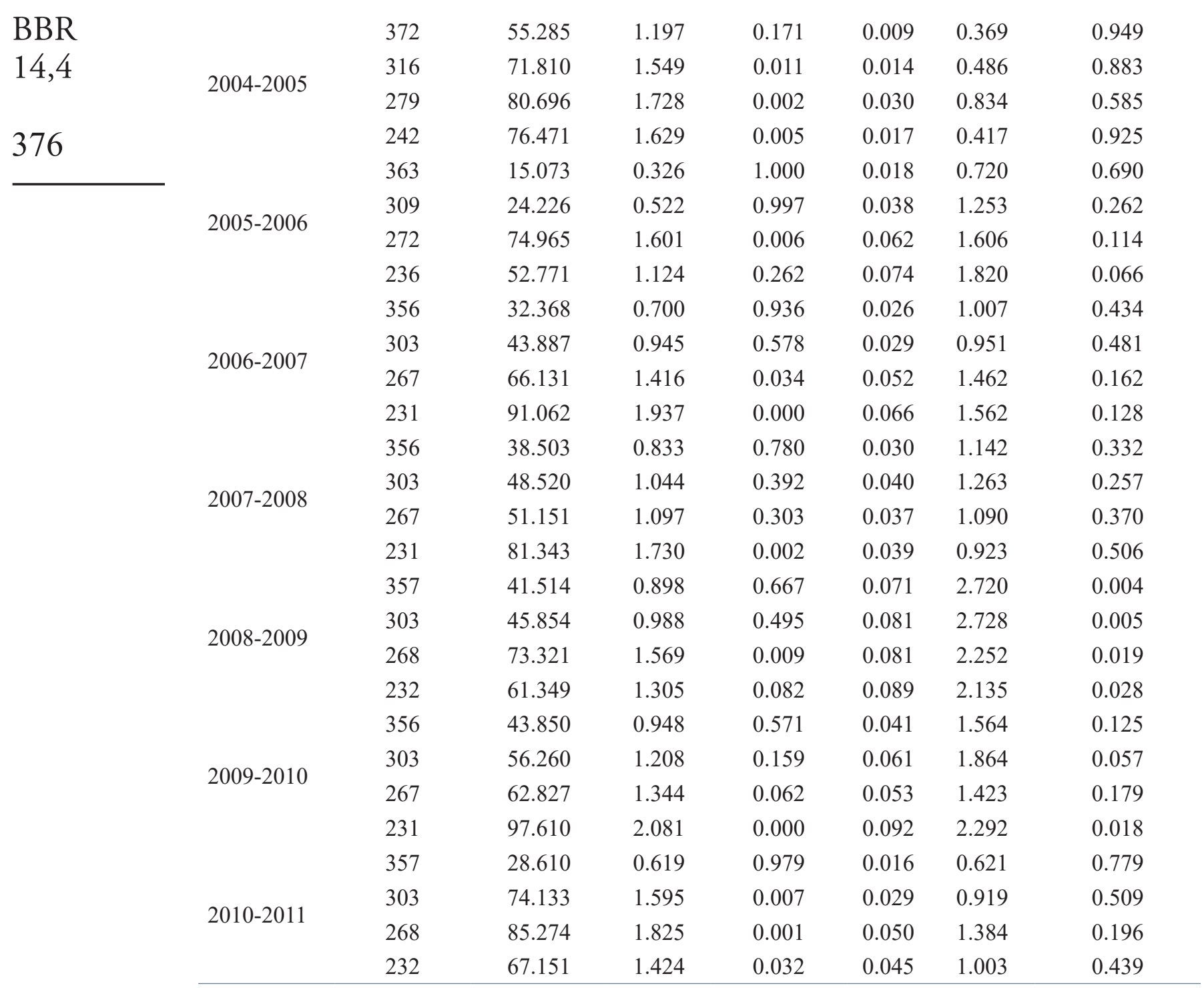

Source: Brazilian Central Bank - BACEN (data used by the authors)
Note: Adjustments used - tests carried out for several random samples of banks obtained by means of a syntax that selected a single random sample that represented a percentage of cases available on the $\mathrm{IBM}^{\circ} \mathrm{SPSS}^{\circ}$.

conditions imposed on them, and as a result there were bankruptcies, mergers, takeovers and privatizations. From these findings, it is expected that different structures of the strategic groups in terms of the number of groups and their composition will take place over the time window defined for this study.

We have identified the strategic groups in each analyzed year through the Model-Based Clustering or MCLUST MCLUST (Banfield and Rafteri, 1993). This cluster technique enables researchers to get the best possible solution (number of clusters) through iterative EM (expectation-maximization) methods for maximum likelihood clustering with parameterised Gaussian mixture models. The procedure used to determine the optimal number of clusters was the Bayesian Information Criterion (BIC). Table 4 summarizes the number of strategic groups identified in each of the years considered in the study, the number of new strategic groups, those which disappeared, reappeared and persisted as well as the net change taking place with time.

During the time period of this study, the number of groups has varied between 3 and 9. Periods which presented more groups have been followed by periods with more groups disappearing. Such period correspond to years of great environmental disturbance, for 
Table 3. Possible environmental cause of break in the stable time periods

\begin{tabular}{ll}
\hline Date & Environmental Disturbances \\
\hline 1994 & Implementation of Plano Real (Real Plan) and process of price stabilization: revenues deriving \\
& from inflation fell and banks started to earn income by increasing credit and charging fees \\
& for banking services. Brazil's adoption of Basel Accords and demand for a minimum capital \\
& to be kept by banks in relation to the risk of their active operations. \\
& Restrictive monetary and credit policy and increase in the insolvency level: rise in the reserve \\
& requirement ratio, introduction of other means of control over credit creation and increase \\
& in the basic interest rates in order to reduce liquidity in the system. The crisis of two big \\
& banks - Econômico and Nacional - became the trigger for a systemic crisis which resulted \\
& in a process of financial deregulation, openness to foreign capital linked to the acquisition of \\
& banks in trouble and the institution of Proer with the aim of ensuring liquidity and solvency \\
& in the system.
\end{tabular}

Privatization of state banks: by means of Proes, the state government financed the restructuring privatized, 7 became federal banks for posterior privatization and 5 were restructured.

External crises due to contagion of Russian and Asiatic crises: banks adjusted their equity

1997 to 1999 structure by increasing the participation in the asset composition of investments in currencylinked government bonds and overnight rate. This change provided a currency hedge against the currency devaluation in 1999

\begin{tabular}{|c|c|}
\hline 2000 & $\begin{array}{l}\text { The dot-com bubble: a speculative bubble during which there was a rapid rise in equity } \\
\text { markets fueled by investments in internet-based companies. }\end{array}$ \\
\hline 2001 & $\begin{array}{l}\text { Adaptation of public banks: due to the establishment of Proef, public national financial } \\
\text { institutions became capitalized as well as subject to the same discipline (regulation) to which } \\
\text { private banks must comply, thus they would become more 'transparent'; } \\
\text { The world trade center terrorist attack: The effects arising from this attack were initial shock } \\
\text { causing global stock markets to drop sharply. }\end{array}$ \\
\hline $\begin{array}{l}2002 \text { and } \\
2003\end{array}$ & $\begin{array}{l}\text { Turbulence in the Latin American financial market and global risk aversion: downturn in the } \\
\text { expansion of foreign banks in Brazil. Some foreign banks (such as Sudameris do Brasil and } \\
\text { BBV Banco) that could not create sufficient scale to compete in the retail sector sold their } \\
\text { assets in the country. }\end{array}$ \\
\hline $\begin{array}{l}2004 \text { and } \\
2005\end{array}$ & $\begin{array}{l}\text { Perspective of stabilization of internal prices and exchange rates: there was a new expansive } \\
\text { cycle in credit focused especially on financing for households. Big retail banks invested in the } \\
\text { acquisition/creation of investment, financing and credit societies and entered into partnerships } \\
\text { with retail chains. Small-sized and medium-sized conglomerates started to sign agreements } \\
\text { with municipal, state and federal public entities and with privately held companies with the } \\
\text { purpose of providing payroll-linked loans. }\end{array}$ \\
\hline $\begin{array}{l}2008 \text { and } \\
2009\end{array}$ & $\begin{array}{l}\text { Subprime crisis: the external crisis constricted Brazilian banks and firms' access to external } \\
\text { lines of credit and also affected the capital and foreign exchange markets in the country. The } \\
\text { government and the Central Bank tried to minimize the impact of such crisis in the Brazilian } \\
\text { financial sector by means of a series of measures among which were the reduction of the } \\
\text { reserve requirement. However, banks lost value due to the confidence crisis that troubled } \\
\text { worldwide financial markets. }\end{array}$ \\
\hline 2011 & $\begin{array}{l}\text { Crisis in the Eurozone: Brazilian subsidiaries of European banks started to present the need } \\
\text { for capitalization given the exclusion of the international market for fundraising. }\end{array}$ \\
\hline
\end{tabular}

instance 2002 and 2003, when there have been economic disturbances in South American countries, including Brazil. These findings may be considered an indication that banks change their competitive strategies in response to changes in environmental conditions.

Moreover, 29 (twenty-nine) strategic groups having been identified in the period from 1994 to 2011, this number of groups being proportionately (considering the number of 
BBR

14,4

378

banks and the time window of the study) in line with the Zúñiga et all (2004) study in which 24 (twenty-four) strategic groups were identified in the Spanish banking industry.

We emphasize that only 4 (four) of these strategic groups last over practically the whole time window of the study, thus around 23 (twenty-three) of these may be considered as transitory groups and we will detail this definition further on in this section.

In order to identify the strategies that distinguish one group from another, following the procedure used by Amel \& Rhoades (1988), we compared the average values of the strategic variables of each group with the industry average.

From the total groups thus identified, around 6 (six) of these described in Table 5, can be considered as basic models of strategic conduct of Brazilian banks (four remain over the time window of the study and two disappear in one particular year and reappear the following year). The other groups appear and disappear over the years and therefore can be seen as transitory competitive patterns (or transitory strategic groups).

With regard to the banks taken as basic models of strategic conduct, the retail banks, credit and treasury banks provide full banking services, whereas the interbank operating, business and transfer banks would be the intermediaries of banking intermediation, i.e., are intermediaries within the system, who aim to guarantee the liquidity of the others.

The banks taken as transitory, the justification for said conduct is based on the Gonzalez; Savoia \& Gouvêa (2008) study, where the authors emphasize that interbank operating are not a long-term profitable activity, since the donor bank incurs a high cost of maintaining a banking structure without the benefit of the ample margins of banking spreads.

Notice therefore, that some of the transitory groups (those who appear and disappear over the study time window) are comprised of these interbank operating banks that have recently increased their credit portfolio, but do not yet express credit income by virtue of the incipient maturity of the loans then granted.

A part of these transitory groups is also comprised of banks that have shown a meaningful credit portfolio in previous periods, i.e., were credit banks. However, they are at a review phase of their activity strategy, reducing their risk exposure in credit transactions, or by treasury and business banks in the process of increasing their credit portfolio.

In years of great environmental upheaval, an increase in these strategic groups followed by these decreases can be clearly seen. The years 2002 and 2003 were marked by economic upheavals in South American countries (Argentina and Brazil among them).

On the international scenario, the Nasdaq Crisis drove investors to an aversion to risk, thus the surge of the Argentine Crisis that culminated in devaluation and collapse of the State, had a negative effect on Brazil. Adding to the confused international context, the presidential election, in which the left-wing candidate, Luis Ignácio Lula da Silva, was leading the polls, triggered a negative reaction in the financial market due to the fear that the future government might change the economic policy.

In the beginning of 2002, government bonds issued by the National Treasury and the Central Bank lost value and the reputation of Brazilian government debt was called into question in the face of the growth in the aversion to risk, and credit was rationed. This year, we saw an increase in the number of transitory groups that indicated a strategic repositioning of Brazilian banks. Thus in 2003, only three strategic groups are observed (interbank operating, treasury and retail banks), the strategic rank of these banks being in line with the context of credit rationing. There was also a retraction in the expansion of foreign banks in Brazil marked by the shutting down of activities in the country by some of those banks.

The Sub-Prime crisis is another period worth highlighting. The overseas crisis restricted access by banks and companies to foreign credit in Brazil, besides affecting the capital and exchange markets in the country. The Government and the Central Bank had to take measures to minimize the impact of this crisis. Among these measures, those of credit lines 


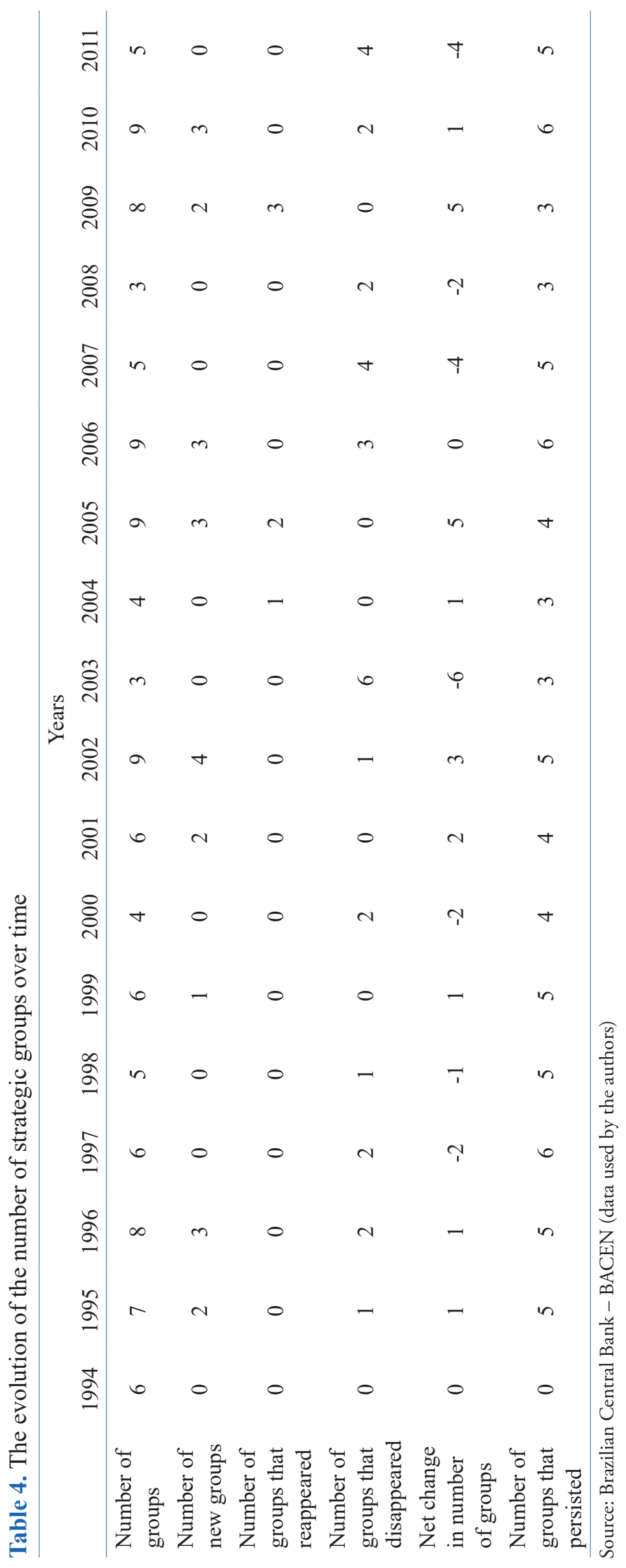

BBR

14,4

379 
BBR

14,4

Table 5. The most stable strategic groups and the frequency of disappearances

\begin{tabular}{lll}
\hline Period & Strategic Group & Main Strategic Characteristics \\
\hline Stable strategic groups with a lesser frequency of disappearance
\end{tabular}

Stable strategic groups with a greater frequency of disappearance

$1994-1999, \quad$ Transfer Banks

$2001-2002,2005$

-2007 and 2009 -

2011

Like credit banks, these banks are specialized in credit transactions, although they are different from credit banks with regard to the origin of resources, once they do not derive their raising of capital from significant deposits, and their principal source of funds is in their obligation accounts due to loans and transfers (an account mainly made up by loans from the BNDES (Brazilian Development Bank) system. These are funds distributing banks that have neither the size nor the funds to maintain a branch structure.

$2005-2006$ and Business Banks $2009-2010$

These are low leverage banks with high service revenues, and therefore show no preponderance in their asset accounts. These banks can adopt a strategy of interbank investment (DI) and in treasury, as an alternative to seasonal conditions or low demand for their services for the placement and issuance of private securities.

Source: Brazilian Central Bank - BACEN (data used by the authors)

are reflected in the strategic rank of the banks in 2008, the year in which we observed three strategic groups (interbank operating, credit and retail banks), two of which are mainly orientated to the extending of credit.

In the light of the results shown so far, we may infer that the evolution of the Brazilian banking industry has been marked by periods of strategic instability. They have redirected their strategy to deal with the new environmental contexts. Some of the strategic groups seen are comprised of transitory groups made up of banks that are repositioning their competitive strategy toward a competitive pattern, i.e., they are making incremental changes in their strategy, reconfiguring their asset base in order to compete under the new market conditions.

With regard to a viable strategic pattern, these groups have a tendency to grow. More and more, other banks start to follow those that have been shown to be successful. In order to substantiate the changes in the group arrangements (number of group members), we calculated the mobility rates between strategic groups for each period. To build this index, we recorded the number of times that banks moved from one particular group to another one, as well as the number of times they remained in the same group. 
On comparing the strategic groups over consecutive periods, in cases where the same banks belonged to identical groups in both periods, we can state that there is no mobility, since there are no changes in the make up or structure of the groups in said periods. Mobility arises at the time that any bank differs from the group when there are significant differences in the composition of the groups.

Our results show a mobility rate that oscillates between 0.455 and 0.745 , indicating a relatively high level of mobility between the strategic groups. On average, according to Table 6 , about $61.1 \%$ of the banks changed their strategic rank over the time window of this study.

Table 6. Mobility rate among strategic groups

\begin{tabular}{lccccccccccccccccccccc}
\hline \multicolumn{11}{c}{ Years } \\
\hline & $94-95$ & $95-96$ & $96-97$ & $97-98$ & $98-99$ & $99-00$ & $00-01$ & $01-02$ & $02-03$ & $03-04$ & $04-05$ & $05-06$ & $06-07$ & $07-08$ & $08-09$ & $09-10$ & $10-11$ \\
\hline $\begin{array}{l}\text { Mobility } \\
\text { Rate }\end{array}$ & 0.523 & 0.538 & 0.683 & 0.460 & 0.642 & 0.695 & 0.736 & 0.647 & 0.745 & 0.466 & 0.694 & 0.625 & 0.556 & 0.455 & 0.669 & 0.584 & 0.664
\end{tabular}

Source: Brazilian Central Bank - BACEN (data used by the authors)

Note: Mobility Rate $=0$ : there is no mobility, perfect strategic stability.

Mobility Rate $=1$ : Full mobility, perfect strategic instability.

This level of mobility evidences greater instability in the strategic patterns of an industry represented by a population of companies, also made up of small firms as is the case of the Brazilian banking market.

Moreover, our findings that there is a reduction in the number of strategic groups in years when there are changes in environmental conditions may be related to the fact that groups whose strategic standard is viable (apparently those whose strategy would make them successful) tend towards growing as they attract other banks in their direction; it is also corroborated by the literature on bank concentration. This literature suggests that crises are less likely to happen in economies in which there is bank concentration. It also suggests that this concentration provides firms with more profits than normal. Therefore, market concentration increases market power and also bank profits, as it enables them to raise the interest rate (Becker et al 2006).

\section{CONCLUSIONS}

From the restrictions shown by Zúñiga et al (2004) with regard to the empirical studies that looked into (from a dynamic perspective) the basic questions about the make up of strategic groups, their evolution and types of changes to which they have suffered, our study looked into questions such as the dynamics of the competitive structure and the competitive ranking of the firms and the Brazilian banking industry. For this analysis, we considered a period characterized by instability in the environmental conditions, as well as an unstable sample of banks (they "are born" and disappear over the period of the study time window), these being comprised not only of the largest banks in the industry, but also of small banks.

Initially we recognized by means of statistical techniques (among them the Box's M and Hotelling's $\mathrm{T}^{2}$ tests), the existence of periods of great strategic instability in the Brazilian banking industry. One of the reasons now attributed for said existence would be strictly related to continuous environmental upheavals that took place in the sector over the period.

With regard to said environmental upheavals, we also highlighted that taking into account a sample of banks also comprising small banks, it would have been difficult to find periods of strategic stability, since each bank reacted differently to the environmental 
BBR

14,4

upheavals. From these first findings, we began to look into the occurrence of different strategic group structures in terms of the number of groups and their composition by means of the identification of these groups over the time window defined for this study.

Over the 18 years covered by this study, various strategic group structures, in terms of group numbers, have been observed. Several empirical studies (Cool, 1985; Cool \& Schendel, 1987; Fiegenbaum, 1987; Mascarenhas, 1989; Fiegenbaum \& Thomas, 1990) provide strong evidence with regard to the existence of periods of strategic stability, in addition to a certain stability not only in the number of strategic groups identified, as well as the pattern of competitive conduct of each group and low mobility among the strategic groups in the long run. This study, for its part, confirms the work of Zúñiga et al (2004), providing empirical evidence that from a sample of large and small firms that have been subject to the instability of environmental conditions over time, it was hard to find a period of complete strategic stability.

This finding means that at some time, there is a change in the strategic rank of these firms that enables an understanding of the evolution of the competitive patterns of an industry over time.

Individually, the banks also change their competitive rank. The average mobility rate of the Brazilian industry was high (on average around $61.1 \%$ of the banks changed their strategic rank) in relation to other empirical studies and very close to the results of Zúñiga et al (2004) on the Spanish banking industry.

We highlight that this result must be considered with caution, since the probability of changes in the individual strategic rank of banks measured by means of the mobility rate of the Brazilian banking industry was very different for each year considered. A possible justification for this could be related to the fact that the people who manage each bank react differently to each environmental change. It would be worthwhile to look into the existence of mimicry whenever a new strategy emerges. In this context, the good performance of some members of a particular dominant group would also be observed in the others, in the long run.

\section{REFERENCES}

AMEL, D. ; RHOADES, S. A. Strategic groups in banking. The Review of Economics and Statistics, v. 70, p. 685-689, 1988.

AMEL, D. ; RHOADES, S. A. The performance effects of strategic groups in banking. The Antitrust Bulletin, V. 37, p. 171-186, 1992.

BANCO CENTRAL DO BRASIL. Informações Contábeis: Balancetes, available at www.bcb.gov.br.

BECK, T.; DE JONGHE, O.; SCHEPENS, G. (2013). Bank competition and stability: cross-country heterogeneity. Journal of financial Intermediation,22(2), 218-244.

BECK, T.; DEMIRGÜÇ-KUNT, A.; LEVINE, R. (2006). Bank concentration, competition, and crises: First results. Journal of Banking \& Finance, 30(5), 1581-1603.

BOGNER, W. C. Patterns of intra-industry competition: A dynamic analysis of theoretical foundations of strategic groups. Doctoral Thesis, University of Illinois at Urban-Champaign, 1991.

CAVES, R. E.; PORTER, M. From entry barriers to mobility barriers: conjectural decisions and contrived deterrence to new competition. Quarterly Journal of Economics, v. 91, p. 241-26, 1977.

COOL, K. Strategic group formation and strategic group shifts: a longitudinal analysis of the U.S. Pharmaceutical. Doctoral Thesis, Purdue University, 1985.

COOL, K.; SCHENDEL, D. Strategic group formation and performance: the case of the U.S. pharmaceutical industry, 1963-82. Management Science, v. 33, p. 1102-1124, 1987.

COOL, K.; SCHENDEL, D. Performance Differences Among Strategic Group Members. Strategic Management Journal, v. 9, p. 207-223, 1988.

FIEGENBAUM, A. Dynamic Aspects of Strategic Groups and Competitive Strategy: concepts and empirical examination in the Insurance Industry. Doctoral Thesis, University of Illinois at Urban-Champaign, 1987. 
FIEGENBAUM, A.; THOMAS, H. Strategic Groups and Performance: The U.S. Insurance Industry, 197084. Strategic Management Journal, v. 11, p. 197-215, 1990.

FIEGENBAUM, A.; THOMAS, H. Industry and Strategic Group Dynamics: Competitive Strategy in the Insurance Industry, 1970-84. Journal of Management Studies, v. 30, p. 69-105, 1993.

FIEGENBAUM, A.; THOMAS, H. Strategic groups as reference groups: theory, modeling and empirical examination of industry and competitive strategy. Strategic Management Journal, v. 16, p. 461-476, 1995.

FIEGENBAUM, A.; SUDHARSHAN, D.; THOMAS, H. The concept of stable strategic time periods in strategic groups research. Managerial and Decision Economics, v. 8, p. 139-148, 1987.

FIEGENBAUM, A.; SUDHARSHAN, D.; THOMAS, H. Strategic time periods and strategic groups research: concepts and an empirical example. Journal of Management Studies, v. 27, p. 133-148, 1990.

FLAVIÁN, C.; HABERBERG, A.; POLO, Y. Food retailing strategies in the European Union. A comparative analysis in the UK and Spain. Journal of Retailing and Consumer Services, v. 9, p. 125-138, 2002.

FLAVIÁN, C.; POLO, Y. Competitive strategies in Southern Europe: the case of Spanish retailers. International Journal of Retail \& Distribution Management, v. 26, p. 13-28, 1998.

GARCÍA, M. T.; SANTOS, M. V.; VELLELADO, E. Grupos estratégicos en las cajas de ahorro españolas: dinámica temporal, consistencia interna y resultados. Cuadernos de Economía y Dirección de la Empresa, v. 10, p. 432-461, 2001.

GONZALEZ, R. B.; SAVOIA, J. R.; GOUVÊA, M. A. Grupos estratégicos bancários: uma abordagem transversal multivariada para o problema da segmentação dos bancos no Brasil. RAM - Revista de Administração Mackenzie, v. 9, n. 7, p. 11-40, 2008.

HATTEN, K. J. Strategic Models in the Brewing Industry. Doctoral Thesis, Purdue University, 1974.

HATTEN, K. J.; HATTEN, M.L. Strategic Groups, Asymmetrical Mobility Barriers and Contestability. Strategic Management Journal, v. 8, p. 329-342, 1987.

HUNT, M. Competition in the Major Home Appliance Industry, 1960-70. Doctoral Thesis, Harvard University, 1972.

KETCHEN, D. J.; THOMAS J. B.; SNOW C. C. Organizational Configurations and Performance: A Comparison of Theoretical Approaches. Academy of Management Journal, v. 36, p. 1278-1313, 1993.

MÁS, F. J. Dynamic analysis of competition in marketing: strategic groups in Spanish banking. International Journal of Bank Marketing, v. 17, p. 233-250, 1999.

MÁS, F. J. Predicción de la estructura future de la indústria. La teoría de grupos estratégicos. Economía Indústrial, v. 311, p. 193-201, 1996.

MASCARENHAS, B. Strategic Groups Dynamics. Academy of Management Journal, v. 32, p. 333-352, 1989.

MASCARENHAS, B.; AAKER, D. A. Mobility Barriers and Strategic Groups. Strategic Management Journal, v. 10, p. 475-485, 1989.

MCGEE, J.; THOMAS, H. Strategic Groups: Theory, Research and Taxonomy. Strategic Management Journal, v. 7; p. 141-160, 1986.

NEWMAN, H. H. Strategic Groups and the Structure-Performance Relationship: A Study with Respect to the Chemical Process Industries. Doctoral Thesis, Harvard University, 1973.

NEWMAN H. H. Strategic groups and the structure-performance relationship. Review of Economics and Statistics, v. 60, p. 417-427, 1978.

OSTER, S. M. Intraindustry structure and the ease of strategic change. Review of Economics and Statistics, v. 64, p. 376-383, 1982.

PATTON, G. R. A Simultaneous Equation Model of Corporate Strategy: The Case of the U.S. Brewing Industry. Doctoral Thesis, Purdue University, 1976.

PORTER, M. E. Consumer Behavior, Retailer Power, and Manufacturer Strategy in Consumer Goods Industries. Doctoral Thesis, Harvard University, 1973.

PORTER, M. E. Interbrand Choice, Strategy and Bilateral Market Power. Cambridge: Harvard University Press, 1976.

PORTER, M. E. The structure within industries and companies performance. Review of Economics and Statistics, v. 61, p.214-227, 1979.

SAVOIA, J. R. F.; WEISS, J. Uma aplicação de análise multivariada para a estrutura de ativos e passivos de bancos. In: CLADEA-CONSEJO LATINOAMERICANO DE ESCUELAS DE ADMINISTRACION, Jul. 1995, Monterrey Anais. Monterrey: CLADEA, 1995. 
BBR

14,4

384
SUDHARSHAN, D.;THOMAS, H.; FEIGENBAUM, A. Assessing mobility barriers in dynamic strategic groups analysis. Journal of Management Studies, v. 28, p. 429-438, 1991.

TRIBUNAL DE CONTAS DA UNIÃO. Contas do Governo da República: Exercício de 2009, available at www.tcu.gov.br.

ZÚÑIGA VICENTE, J. A.; FUENTE SABATÉ, J. M.; SUÁREZ GONZÁLEZ, I. Dynamics of the strategic group membership-performance linkage in rapidly changing environments. Journal of Business Research, v. 57, n. 12, p. 1378-1390, 2004. 